\title{
Fazer melhor, e não menos ${ }^{\dagger}$
}

David Kupfer*

É até difícil acreditar que, passados dez anos, as reservas internacionais do Brasil superem hoje a casa dos US $\$ 250$ bilhões, quase nove vezes mais que os US $\$ 29,2$ bilhões registrados pelo Banco Central em julho de 2000. Tampouco parece crível que o país seja hoje credor líquido em divisas quando se relembra que no mesmo julho de 2000 a dívida externa líquida do setor público era de US\$ 108 bilhões, quase 10\% do PIB e mais de três vezes o valor das exportações do país. Porém, se não há dúvida de que os últimos dez anos representaram uma dádiva para as contas externas da economia brasileira, isso não quer dizer que o país tenha se livrado definitivamente da praga da escassez de divisas, que historicamente sempre constituiu um dos principais entraves ao desenvolvimento econômico. Por isso, é fundamental que os atores governamentais e empresariais não se acomodem durante essa temporada de bonança cambial e, ao contrário, aproveitem o quadro macroeconômico favorável para impulsionar as necessárias transformações estruturais requeridas para a sua sustentação no longo prazo.

Dentre essas transformações, uma primeira questão que precisa ser melhor compreendida e incorporada com a devida ênfase no debate sobre os rumos da indústria brasileira são as novidades que vêm se desenhando nas formas de organização da produção industrial global, particularmente no que diz respeito à distribuição espacial das cadeias produtivas. A chamada especialização vertical, também conhecida como modelo de produção fragmentada, no qual empresas - e países - se dedicam a produzir insumos específicos em etapas sequenciais de atividades de montagem distribuídas internacionalmente, implica maior interpenetração dos sistemas produtivos nacionais, exigindo que os países se qualifiquem para participar simultaneamente como origem e destino das transações envolvendo mercadorias, capitais e tecnologias. Evidentemente, a difusão desse sistema de especialização vertical traz novos desafios para as empresas brasileiras, fazendo da agenda de integração regional algo muito além da busca de parceiros visando meramente obter maior escala de demanda. O que entra em questão é a construção de espaços efetivos de compartilhamento de atividades produtivas com o objetivo de incrementar a eficiência operacional dos empreendimentos.

Um segundo foco que necessita ser incorporado à reflexão vem das importantes mu-

\footnotetext{
†Artigo publicado no jornal Valor Econômico em 8 de setembro de 2010.

*Doutor em economia da indústria e da tecnologia e professor da Universidade Federal do Rio de Janeiro (UFRJ), coordenador do Grupo de Indústria e Competitividade (CIG-IE/UFRJ). Endereço eletrônico:gic@ie.ufrj.br.
} 
danças em curso no mundo empresarial. Aqui o que se observa é mais uma rodada em um processo gradual, longo e provavelmente irreversível no qual as empresas estão se desmaterializando, tornando-se cada vez mais apoiadas em ativos intangíveis e menos dependentes de ativos tangíveis.

Mais ainda do que a empresa flexível - aquela capaz de elaborar muitos produtos a partir de muitos insumos, ajustando-se rapidamente a mudanças nas condições da oferta e nos padrões da demanda - que foi se formando no final do século passado, observam-se agora formações empresariais extremamente ágeis que, por meio de parcerias, joint ventures ou outras formas de associação de capital modificam pautas de produtos e bases geográficas com enorme rapidez.

Evidentemente, transformações dessa profundidade na indústria mundial, ainda mais diante da emergência da China como potência econômica, assumem grande importância no reposicionamento estratégico das empresas brasileiras, razão pela qual o redesenho da política industrial e tecnológica nacional torna-se desejável. Provavelmente, o país tenderá a tornar-se cada vez mais importador e exportador das mesmas classes de mercadorias, aprofundando o comércio intraindustrial e aproximando-se, assim, do padrão vigente em economias de industrialização mais avançada.

Analogamente, existirão cada vez mais empresas transnacionais atuando no Brasil, o que não é propriamente uma novidade, mas vai se observar um número crescente de empresas brasileiras com atuação relevante no exterior. Enfim, o país está caminhando para uma estrutura produtiva e empresarial mais complexa, na qual irá preponderar uma maior intensidade de competição e colaboração com o exterior.

A chave para acelerar essas transformações está na mudança da ênfase da política industrial e tecnológica da busca de competitividade, no sentido convencional de desempenho, para a criação de competências, no sentido de fomentar o surgimento de capacitações produtivas e inovativas compatíveis com os requisitos de eficiência e qualidade desse novo quadro internacional. Condições macroeconômicas para propiciar essa transição existem. O desafio crucial está em encontrar novos instrumentos de política, pois é certo que os incentivos e as regulações tradicionais não se aplicam a cadeias produtivas desintegradas internacionalmente e muito menos a empresas que apresentam as estruturas patrimoniais mais flexíveis aqui mencionadas. Tal como sugere o professor Robert Wade, da London School of Economics, em carta publicada na "The Economist" dessa semana ${ }^{1}$, ainda repercutindo o debate recentemente 1 Sep 2 and 2010. The Economist. Letters.

\section{Government industry}

Robert H. Wade. 
veiculado pela revista, a questão central sobre a política industrial ainda é como fazer melhor - e não como fazer menos.

\footnotetext{
SIR - Recent interest in industrial policy ("Picking winners, saving losers"), August 7th) has turned the discussion to how and when to do it better, rather than simply how to do it less. The distinction between leading and following the market is useful. Public investment in new industries where private investors have shown little interest ("leading") is obviously riskier than where the private sector has already had some success ("following"). Leading can be made less risky by studying products being made in economies with incomes two- or three-times higher to see what domestically-based firms might be able to upgrade to or diversify into.

However, public assistance must be given against performance indicators, which may relate to export success, or product quality, or prices moving towards international levels. Failure to specify performance conditions has been the bane of industrial policy from India to New Zealand. And as for how to improve success - it is worth bearing in mind the dictum attributed to Thomas Watson, founder of IBM, "If you want to be more successful, increase your failure rate."

Professor Rober H. Wade.

Department of Internacional Development.

London School of Economics.

London.
} 
